\title{
Restricted distribution of Streptococcus milleri carbohydrate type antigens amongst other viridans streptococci
}

\author{
M. INOUE, NOBUKO MATSUNOSHITA and T. YAKUSHIJI
}

\author{
Department of Preventive Dentistry, Kagoshima University Dental School, 8-35-1 Sakuragaoka, Kagoshima 890, \\ Japan
}

\begin{abstract}
Summary. The distribution of oral Streptococcus milleri carbohydrate type antigens in other viridans streptococcus species was examined. Rantz-Randall extracts of cells of the test strains grown in broth containing glucose were allowed to react with typing or grouping antisera for $S$. milleri serotypes $a-k$, or Lancefield groups A-G and K. Of 93 strains comprising more than 12 streptococcal species that included $S$. mutans and $S$. sanguis complexes, only $15 S$. salivarius strains and one $S$. mitis strain were immunologically related to $S$. milleri serotype $f$. Unlike $S$. milleri strains, $S$. salivarius type $f$ strains belonged to Lancefield group K, whereas the $S$. mitis strain was closely related to $S$. milleri serotype $f$ but did not react with any of the Lancefield grouping antisera tested. Results suggest that oral $S$. milleri strains can be distinguished serologically from other oral viridans streptococci and that the typing antisera used in our researches might differentiate $S$. milleri isolates from the mouth from those associated with systemic purulent infections.
\end{abstract}

\section{Introduction}

Viridans streptococci designated Streptococcus milleri are commensal organisms on mucosal surfaces in the oral cavity, nasopharynx and gastrointestinal tract. Pathogenic strains are frequently isolated from purulent lesions in various systemic infections. ${ }^{1-3}$ However, these clinically important streptococci comprise a biochemically and genetically heterogeneous collection of strains referred to variously as Streptococcus MG, S. intermedius, S. anginosus or S. constellatus. ${ }^{3-10}$ Their taxonomic status is still unclear.

$S$. milleri strains are also serologically heterogeneous; many investigators have demonstrated that they frequently carry Lancefield group antigens F, A, $\mathrm{C}$ or $\mathrm{G},{ }^{11,12}$ or Ottens type antigens I to $\mathrm{V},{ }^{13}$ or both. Our recent studies divided oral $S$. milleri isolates into at least 11 serotypes, $a-k \cdot{ }^{14,15}$ Approximately $80 \%$ of oral $S$. milleri isolates ${ }^{14,15}$ and $40 \%$ of isolates from systemic purulent infections ${ }^{16}$ have been identified to one of the serotypes. In this regard, it is of interest to know the distribution of $S$. milleri type antigens in the many other species of viridans streptococci indigenous to the oral cavity. The present study examined the possibility of distinguishing serologically $S$. milleri from other viridans streptococci and assessed the usefulness of typing antisera for identifying oral $S$. milleri in systemic foci. In this study, the term $S$. milleri is used as recommended. ${ }^{17}$

\section{Materials and methods}

\section{Streptococcal strains}

Ninety-three strains of more than 12 viridans streptococcal species were examined (table). The reference strain of $S$. milleri serotype $f$. ATCC 9895 (Lancefield group F), was also used as required, as in previous studies of serotypes. ${ }^{14,15}$

Streptococcal strains were grown in Brain Heart Infusion (BHI) Broth (Difco) anaerobically at $37^{\circ} \mathrm{C}$ overnight.

\section{Immunological methods}

Cell-surface carbohydrate antigens were extracted from cells grown in broth containing glucose by the method of Rantz and Randall ${ }^{18}$ as described previously. ${ }^{14}$ The $11 S$. milleri type-specific antisera, $a-k$, were prepared as before. ${ }^{14,15}$ Lancefield group antisera $(A-G, K)$ were purchased from Difco Laboratories.

Reactivity of antigen extracts with the typing antisera was first examined in a capillary precipitation test at room temperature for up to $30 \mathrm{~min}$. To confirm the specificity of the precipitin reaction for $S$. milleri type antigens, double immunodiffusion analysis was performed in a Noble Agar (Difco) $1 \%$ plate. ${ }^{14}$ The antigen preparations that reacted with the typing sera were examined further for reactivity with the Lancefield grouping antisera in similar tests.

\section{Results}


Table. Reactivity of viridans streptococcal strains with $S$. milleri typing antisera and Lancefield grouping sera

\begin{tabular}{|c|c|c|c|c|}
\hline \multirow{2}{*}{$\begin{array}{l}\text { Streptococcal } \\
\text { species }\end{array}$} & \multirow{2}{*}{ Strain nos. } & \multirow{2}{*}{$\begin{array}{l}\text { Number of } \\
\text { strains }\end{array}$} & \multicolumn{2}{|c|}{$\begin{array}{l}\text { Serological } \\
\text { reactivity }\end{array}$} \\
\hline & & & Serotype & Group \\
\hline \multirow[t]{2}{*}{ S. salivarius } & 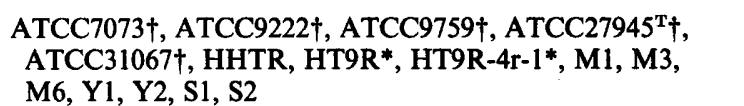 & 15 & $f$ & $\mathbf{K}$ \\
\hline & $\begin{array}{l}\text { ATCC } 9758 \dagger, \text { ATCC } 13419^{\mathrm{T}} \dagger, \text { ATCC } 25975 \dagger, \text { HT } 3 R-3 r-5^{*} \text {, } \\
\text { M2, M4, M5, Y3, Y4, Y5, Y6, S3, S4, S5, S6 }\end{array}$ & 15 & - & - \\
\hline $\begin{array}{l}\text { S. mutans } \\
\text { serotype } a\end{array}$ & HS6 $(S$. cricetus ATCC19462T $)$, HSI, FIL, E49 & 4 & - & nd \\
\hline$b$ & FA1 $(S$. rattus ATCC194645 $)$, BHT & 2 & - & nd \\
\hline$c$ & $\begin{array}{l}\text { OMZ70(S. mutans ATCC33535'), GS5, P2, PK1, Ingbritt, } \\
\text { C67-1, C67-25, MT8148* }\end{array}$ & 8 & - & nd \\
\hline$e$ & P4, B14, LM7, MT703R* & 4 & - & nd \\
\hline$f$ & OMZ175, MT3940* & 2 & - & nd \\
\hline$d$ & B13, P1 & 2 & - & nd \\
\hline$g$ & $\begin{array}{l}\text { K1R, OMZ65, MT3791§, 6715, 6715-11, 6715-DN**, 6715- } \\
\text { DP*, AHT, AHT-M1, AHT-M2, AHT-M9, AHT-M13, } \\
\text { AHT-M35 }\end{array}$ & 13 & - & nd \\
\hline S. sanguis & $\begin{array}{l}\text { ATCC } 10556^{\text {T* }}, \mathrm{OMZ}^{*}, \mathrm{ST} 102^{*}, \mathrm{ST} 107^{*}, \mathrm{ST} 120^{*}, \mathrm{ST} 129^{*}, \\
\text { 9H }\end{array}$ & 7 & - & nd \\
\hline S. gordonii & ATCC $10558^{\mathrm{T} *}, \mathrm{M}-5^{*}$, DL1 & 3 & - & nd \\
\hline \multirow{2}{*}{ S. mitis } & ATCC $33399^{\mathrm{T}} \S$, ATCC $6249^{*}$ & 2 & - & nd \\
\hline & ATCC $903^{*}$ & 1 & $f$ & - \\
\hline S. oralis & ATCC $35037^{\mathrm{T}} \S$, ATCC $10557^{*}$, ATCC $9811 \S, \mathrm{H} 1$ & 4 & - & nd \\
\hline S. parasanguis & ATCC15912 $\ddagger$, ATCC15911 & 3 & - & nd \\
\hline S. intermedius & $31,32,306$ & 3 & - & - \\
\hline$S$. MG & ATCC $15910 \ddagger$ ATCC15913 $\ddagger$ & 2 & - & nd \\
\hline Others & S. faecalis SS499*, S. pyogenes SV*, S. bovis DS96* & 3 & - & nd \\
\hline
\end{tabular}

ATCC, American Type Culture Collection; ${ }^{\text {T }}$, type strain.

Strains were obtained from Drs S. Hamada (Osaka University)*, T. Tsurumizu (Kitasato Institute)†, S. Shizukuishi (Osaka University) $\ddagger$, and T. Koga (National Institute of Health, Tokyo)§, respectively; the others were stock cultures from our laboratory.

$f$, serotype $f ; \mathrm{K}$, Lancefield group $\mathrm{K} ; f-, f$-cross-reactive; - , untypable and ungroupable; nd, not determined.

sera, only $15 S$. salivarius strains reacted with the $f$ antiserum in both the capillary tube and agar gel (table). One strain of $S$. mitis was cross-reactive with $f$ antiserum. The other 77 strains including the 35 "mutans" streptococci and the "sanguis-mitis" complex (20 strains) as well as $S$. salivarius (15 strains) and $S$. mitis (two strains), did not react with any of the typing antisera.

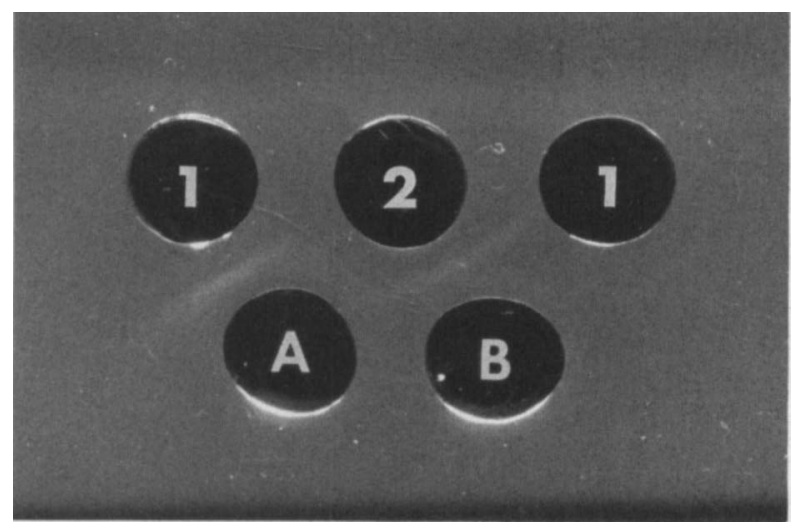

Figure. Immunodiffusion reactions of the Rantz-Randall extracts from the serotype $f$ and group $\mathbf{K} S$. salivarius strains with the anti$f$ and -group K sera. The antigen extract of $S$. salivarius M3 (well 2) produced a precipitin line with the anti- $f$ serum (well A). This completely fused with the line that antigen extracts from the serotype $f S$. milleri reference strain ATCC9895 (well 1) formed with its homologous anti-f $f$ serum, but crossed with the line formed with the anti-group $\mathrm{K}$ serum (well $\mathbf{B}$ ).
In the immunodiffusion analysis, the antigen extracts of $15 S$. salivarius strains produced a precipitin line with type $f$ antiserum which fused completely with that formed between the homologous antigen of the serotype $f$ type strain ATCC9895 (figure). However, the precipitin lines crossed with the line formed with the group $\mathrm{K}$ antiserum. The antigen from one $S$. mitis strain made a precipitin line with $f$ antiserum; this crossed with the line produced between the homologous antigen of the type $f$ reference strain, but did not react with any grouping serum.

\section{Discussion}

Of the 93 strains of various viridans streptococci, mostly indigenous to the oral cavity, only $15 S$. salivarius strains and one $S$. mitis strain were immunologically closely related to oral $S$. milleri (table). The $S$. milleri type $f$ antigen was the only one detected in other viridans streptococci, mainly in S. salivarius. However, the type $f S$. salivarius strains carried simultaneously the Lancefield group $\mathrm{K}$ antigen, whereas the type $f S$. milleri strains, including the type $f$ vaccine strain ATCC 9895 , generally carry the group F antigen. ${ }^{14-16}$ In addition, one $S$. mitis strain crossreacted with type $f$ antiserum, which was not observed with oral $S$. milleri strains. ${ }^{14-16}$ Strains of type $f$ and 
group $\mathrm{K}$ and type $f$-cross-reactive and ungroupable have not been identified in $S$. milleri. These results indicate that the 11 typing sera in the previously proposed typing system for oral S. milleri can be used, particularly in combination with some Lancefield grouping antisera, to distinguish serologically $S$. milleri from other viridans species.

Our previous studies have demonstrated that about $40 \%$ of $S$. milleri isolates from systemic purulent foci carry one of the type antigens found in oral $S$. milleri isolates; their physiological characteristics are also very similar to the oral strains. ${ }^{16}$ However, vaginal isolates of $S$. milleri did not react with any of our typing antisera (unpublished data), which is consistent with earlier findings that vaginal strains are physiologically different from those of oral origin. ${ }^{1}$ This, together with the results presented above, would indicate that the typing antisera could also be used to characterise the oral or non-oral origin of clinical $S$. milleri isolates from systemic foci and might be useful in identifying oral $S$. milleri in systemic infections.

It is known that the strains of $S$. salivarius type I carry Lancefield group $\mathrm{K}$ antige ${ }^{19-22}$ and are immunologically closely related to $S$. MG which carries the common "salivarius" antigen in addition to Lancefield group $\mathrm{F}$ antigen and Ottens type III antigen. ${ }^{23}$

\section{References}

1. Gossling J. Occurrence and pathogenicity of the Streptococcus milleri group. Rev Infect Dis 1988; 10: 257-285.

2. Ruoff KL. Streptococcus anginosus ("Streptococcus milleri"): the unrecognized pathogen. Clin Microbiol Rev 1988; 1: 102-108.

3. Whitworth JM. Lancefield group F and related streptococci. $J$ Med Microbiol 1990; 33: 135-151.

4. Facklam RR. The major differences in the American and British streptococcus taxonomy schemes with special reference to Streptococcus milleri. Eur J Clin Microbiol 1984; 3: 91-93.

5. Kilpper-Bälz R, Williams BL, Lüttiken R, Schleifer KH Relatedness of 'Streptococcus milleri' with Streptococcus anginosus and Streptococcus constellatus. Syst Appl Microbiol $1984 ; 5$ : 494-500.

6. Ezaki T, Facklam R, Takeuchi N, Yabuuchi E. Genetic relatedness between the type strain of Streptococcus anginosus and minute-colony-forming beta-hemolytic streptococci carrying different Lancefield grouping antigens. Int $J$ Syst Bacteriol 1986; 36: 345-347.

7. Coykendall AL, Wesbecher PM, Gustafson KB. "Streptococcus milleri", Streptococcus constellatus, and Streptococcus intermedius are later synonyms of Streptococcus anginosus. Int J Syst Bacteriol 1987; 37: 222-228.

8. Knight RG, Shlaes DM. Physiological characteristics and deoxyribonucleic acid relatedness of Streptococcus intermedius strains. Int J Syst Bacteriol 1988; 38: 19-24.

9. Whiley RA, Hardie JM. DNA-DNA hybridization studies and phenotypic characteristics of strains within the 'Streptococcus milleri group'. J Gen Microbiol 1989; 135: 2623-2633.

10. Whiley RA, Fraser H, Hardie JM, Beighton D. Phenotypic differentiation of Streptococcus intermedius, Streptococcus constellatus, and Streptococcus anginosus strains within the "Streptococcus milleri group". J Clin Microbiol 1990; 28 : 1497-1501.

11. Ball LC, Parker MT. The cultural and biochemical characters of Streptococcus milleri strains isolated from human sources. J Hyg 1979; 82: 62-78.

12. Colman G, Williams REO. Taxonomy of some human viridans streptococci. In: Wannamaker LW, Matsen JM (eds)
The $S$. milleri type $f$ antigen, which the vaccine strain ATCC 9895 (called $S$. MG or $S$. intermedius) carries, ${ }^{14}$ was detected in $15 S$. salivarius strains (table) and its immunodeterminant was clearly different from that of the group $\mathrm{K}$ antigen (figure). These findings strongly suggest that the $S$. milleri type $f$ antigen is identical to the "salivarius" antigen but not to the Ottens type III antigen.

It should be noted that $c .30 \%$ of $S$. milleri isolates hitherto examined ${ }^{14-16}$ and the five $S$. intermedius or $S$. MG strains tested in this study did not react with any typing antisera (table). Furthermore, recent studies have shown that $S$. salivarius ${ }^{22}$ and $S$. intermedius ${ }^{24}$ can be divided into four and five serovars on the basis of their cell-surface carbohydrate type antigens. Conclusions regarding the immunochemical relationship between $S$. salivarius (particularly type I) and $S$. milleri (particularly $S$. MG or $S$. intermedius) depend upon further chemical and immunological studies on their cell-surface antigenic components.

We thank Drs S. Hamada (Osaka University), T. Koga (National Institute of Health, Tokyo), S. Shizukuishi (Osaka University) and T. Tsurumizu (Kitasato Institute) for providing reference strains and Dr Margaret Duncan (Forsyth Dental Center) for correcting our English. We also thank Ms Izumi Yasunaga for typing the manuscript.

Streptococci and streptococcal diseases. New York, Academic Press. 1972: 281-299.

13. Ottens $\mathrm{H}$, Winkler $\mathrm{KC}$. Indifferent and haemolytic streptococci possessing group-antigen F. J Gen Microbiol 1962; 28: 181-191.

14. Yakushiji T, Kitada K, Okita Y, Inoue M. Distribution of Streptococcus milleri in the oral cavities of Japanese children. Microb Ecol Hlth Dis 1990; 3: 171-179.

15. Yakushiji $\mathbf{T}$, Konagawa $\mathbf{R}$, Oda $\mathbf{M}$, Inoue $\mathbf{M}$. Serological variation in oral Streptococcus milleri. J Med Microbiol 1988; 27 : 145-151.

16. Kitada $\mathbf{K}$, Nagata $\mathbf{K}$, Yakushiji $T$, Eifuku $H$, Inoue $\mathbf{M}$. Serological and biological characteristics of "Streptococcus milleri" isolates from systemic purulent infections. $J$ Med Microbiol 1992; 36: 143-148.

17. Hardie JM. Oral streptococci. In: Sneath, PHA, Mair NS, Sharpe ME, Holt JG (eds) Bergey's Manual of systematic bacteriology, vol. 2. Baltimore, Williams and Wilkins. 1986: 1054-1063.

18. Rantz LA, Randall E. Use of autoclaved extracts of hemolytic streptococci for serological grouping. Stanford Med Bull 1955; 13: 290-291.

19. Mirick GS, Thomas L, Curnen EC, Horsfall FL. Studies on non-hemolytic streptococcus isolated from respiratory tract of human beings; biological characteristics of Streptococcus MG. J Exp Med 1944; 80: 391-406.

20. Williams REO. Streptococcus salivarius (vel. hominis) and its relation to Lancefield's group K. J Pathol Bacteriol 1956; 72: 15-25.

21. Montague EA, Knox KW. Antigenic components of the cell wall of Streptococcus salivarius. J Gen Microbiol 1968; 54 : 237-246.

22. Sato M, Yamasaki T, Tsurumizu T, Okonogi H, Hashimoto T, Shibusawa T. Biochemical and serological characteristics of Streptococcus salivarius. J Dent Health 1990; 40: 325-332.

23. Willers JMN, Ottens H, Michel MF. Immunochemical relationship between Streptococcus MG, F 3 and Streptococcus salivarius. J Gen Microbiol 1964; 37: 425-431.

24. Osano E, Tanaka T, Ozeki M, Makita I, Moriyama T. Serogrouping of oral Streptococcus intermedius. Microbiol Immunol 1990; 34: 211-219. 